\title{
Serum miR-22 may be a biomarker for papillary thyroid cancer
}

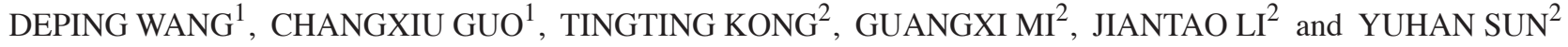 \\ Departments of ${ }^{1}$ Endocrinology and Metabolism, and ${ }^{2}$ Otolaryngology, \\ Hongqi Hospital Affiliated to Mudanjiang Medical University, Mudanjiang, Heilongjiang 157011, P.R. China
}

Received April 25, 2018; Accepted November 23, 2018

DOI: $10.3892 / \mathrm{ol} .2019 .10011$

\begin{abstract}
The present study aimed to examine whether serum microRNA (miR)-22 may be considered a potential biomarker to differentiate patients with papillary thyroid cancer (PTC) from healthy controls. Reverse transcription-quantitative polymerase chain reaction demonstrated that serum miR-22 expression was significantly enhanced in patients with PTC compared with in patients with benign thyroid nodules (BTN) and healthy controls. The expression levels of miR-22 were also increased in the thyroid tissue of patients with PTC compared with in patients with BTN. In addition, increased miR-22 in the serum of patients with PTC was positively associated with metastasis. Furthermore, miR-22 serum levels were increased in patients with PTC and the B-Raf proto-oncogene, serine/threonine kinase V600E mutation. Meanwhile, compared with patients with PTC and $\leq 1 \mathrm{ng} / \mathrm{ml}$ thyroglobulin (Tg)-fine needle aspiration biopsy (FNAB), serum miR-22 was significantly enhanced in patients with PTC and 1-10 ng/ml Tg-FNAB and $>10 \mathrm{ng} / \mathrm{ml}$ Tg-FNAB. A receiver operating characteristic analysis demonstrated that serum miR-22 distinguished patients with PTC from patients with BTN and healthy controls. In conclusion, to the best of our knowledge, the present study was the first to demonstrate that upregulation of serum miR-22 may be used as a potential biomarker to distinguish patients with PTC from healthy controls.
\end{abstract}

\section{Introduction}

Thyroid cancer is a common endocrine malignant tumor, the prevalence of which continues to increase worldwide (1). It has been reported that $\sim 40,000$ patients succumb to thyroid cancer per year, whereas $\sim 300,000$ new patients are diagnosed $(1,2)$. Papillary thyroid cancer (PTC) is the most common type of thyroid cancer and is characterized by a differentiated

Correspondence to: Dr Yuhan Sun, Department of Otolaryngology, Hongqi Hospital Affiliated to Mudanjiang Medical University, 5 Tongxiang Road, Mudanjiang, Heilongjiang 157011, P.R. China E-mail: wang2018422@163.com

Key words: serum miR-22, papillary thyroid cancer, metastasis, biomarker neoplasia (3). BRAF mutations are highly prevalent in thyroid carcinomas, especially $B$-Raf proto-oncogene serine/threonine kinase (BRAF) ${ }^{\mathrm{V} 600 \mathrm{E}}(4)$. Distinguishing PTC from a benign thyroid nodule (BTN), including thyroid adenoma and classical nodular goiter, is crucial for clinicians. Currently, the two most common examination methods, ultrasound (US) and computed tomography, are used to analyze suspect thyroid nodules (5). Furthermore, pre-operative US-guided fine-needle aspiration cytology (FNAC) and intraoperative pathological examination are performed to further explore patients suspected of having PTC (5). However, FNAC sampling is very invasive and therefore limited since it requires multiple aspirations (6). Therefore, the identification of novel non-invasive biomarkers that do not require any invasive procedure is crucial for the early screening of PTC.

MicroRNAs (miRNAs/miRs) are small non-coding RNAs that are key regulators in various physiological and pathological processes, including cell proliferation, cell differentiation and cell death (7-10). Recent studies have revealed that, since circulating miRNAs are very stable in serum and plasma, and present high sensitivity and specificity, they may be considered as novel biomarkers $(11,12)$. Xiong et al $(13)$, demonstrated that miR-126-3p is a tumor suppressor in the progression of thyroid cancer. In addition, miR-375 has been reported to inhibit cell proliferation in thyroid cancer cells by suppressing expression of erb-b2 receptor tyrosine kinase 2 (10). Furthermore, miR-222 and miR-146b are positively correlated with the development of PTC in patients with recurrent PTC (14).

The abnormal expression of miR-22 has been widely reported in various types of cancer, including breast and colorectal cancers $(15,16)$. However, whether miR-22 is dysregulated in PTC has not been investigated. The current study aimed to evaluate the expression of miR-22 in patients with PTC and to further elucidate whether it could be used as a potential biomarker to differentiate patients with PTC from patients with BTN and healthy controls.

\section{Materials and methods}

Patients. The present study was approved by the Research Ethics Committee of the Hongqi Hospital Affiliated to Mudanjiang Medical University (Mudanjiang, China) and all patients provided written informed consent. A total of 150 patients with primary PTC, 100 patients with BTN, and 40 age- and sex-matched healthy controls from the Hongqi Hospital Affiliated to Mudanjiang Medical University were enrolled in 
this study between April 2016 and November 2017. Written informed consent was obtained from all participants. PTC or BTN tissues were extracted from patients, $10 \%$ formalin-fixed at room temperature for $24 \mathrm{~h}$ and paraffin-embedded, and further analyzed for histopathological diagnosis and miRNA examination. The embedded samples were then immediately frozen for total RNA extraction. In addition, blood samples $(5 \mathrm{ml})$ were taken from all subjects prior to surgery, and additional blood samples were collected from six patients after tumor resection and receiving appropriate treatment for 1 week. All blood samples were directly placed into tubes containing sodium citrate. Then, blood samples were centrifuged at $3,000 \mathrm{x} \mathrm{g}$ for $15 \mathrm{~min}$ at $4^{\circ} \mathrm{C}$. Clinical features of the patients included in this study are listed in Table I.

US-guided FNAB. FNAB was performed to aspirate papillary thyroid tissues by endocrinologists using a 25 -gauge needle. After each aspiration, the cytological material was immediately smeared onto slides. The slides were prepared by both air-dried and alcohol-fixed methods (70\% alcohol once, 95\% alcohol twice, absolute alcohol three times, each time for $1 \mathrm{~min}$ at room temperature). The air-dried smears were stained using the Diff-Quik method (17) and immediately evaluated by a cytopathologist, whereas the alcohol-fixed smears were stained by the Papanicolaou method (18) in the cytology laboratory. The sample slide obtained using the Diff-Quik method was then evaluated and classified as 'adequate (sufficient lymphocytes),' 'less than optimal (some lymphocytes),' or 'inadequate (very few or no lymphocytes)'. Another FNA pass was performed without smear, and the sample was collected by rinsing the needle in a tube containing $1 \mathrm{ml} \mathrm{Hank}$ balanced salt solution without heparin. The specimens were immediately transferred to the clinical laboratory and stored at $-20^{\circ} \mathrm{C}$ for 0 to 4 days prior to thyroglobulin $(\mathrm{Tg})$ analysis. For each patient, all passes were performed by the same endocrinologist.

Tg-FNAB antibody assays. The Tg measurements in the needle washouts (Tg-FNAB) were carried out using a commercial immunofluorometric assay (TRA-1-81, Baiao Bolai Bio. Co, Beijing, China) with monoclonal antibodies (DELFIA ${ }^{\circledR}$; PerkinElmer, Inc., Waltham, MA, USA) and a functional sensitivity of $1.0 \mathrm{ng} / \mathrm{ml}$, according to the manufacturer's protocol.

Sample acquisition and RNA extraction. Total RNA from the serum and tissue samples was isolated with RNAVzol LS (Vigorous Biotechnology Co, Beijing, China, http://www. vigorousbiol.com/) according to the manufacturer's protocol. The quality, quantity and integrity of the RNA were monitored using a NanoDrop spectrophotometer (ND-1000; NanoDrop Technologies; Thermo Fisher Scientific, Inc., Wilmington, DE, USA).

Reverse transcription-quantitative polymerase chain reaction $(R T-q P C R)$. The RNA was reverse transcribed into cDNA using the Prime-Script one-step RT-qPCR kit referring to the M-MLV cDNA first strand synthesis system (cat no. C28025-032, Invitrogen; Thermo Fisher Scientific Inc., Waltham, MA, USA) according to the manufacturer's protocol. qPCR was performed using SYBR Green Supermix (Bio-Rad Laboratories, Inc., Hercules, CA, USA) in a Bio-Rad iCycleriQ real-time PCR detection system. The qPCR procedure was performed as follows: $95^{\circ} \mathrm{C}$ for $10 \mathrm{~min}$, followed by 50 cycles of $95^{\circ} \mathrm{C}$ for $10 \mathrm{sec}, 55^{\circ} \mathrm{C}$ for $10 \mathrm{sec}, 72^{\circ} \mathrm{C}$ for $5 \mathrm{sec}, 99^{\circ} \mathrm{C}$ for $1 \mathrm{sec}, 59^{\circ} \mathrm{C}$ for $15 \mathrm{sec}$ and $95^{\circ} \mathrm{C}$ for $1 \mathrm{sec}$, after which, samples were cooled to $40^{\circ} \mathrm{C}$. U6 was used as an internal reference gene. The relative expression levels were calculated using the $2^{-\triangle \Delta C q}$ method (19), and the experiments were repeated in triplicate. The primers used in the current study were as follows: miR-22-RT, 5'-GTCGTATCCAGT GCAGGGTCCGAGGTATTCGCACTGGATACGACTAAG C-3'; U6-RT, 5'-GTCGTATCCAGTGCAGGGTCCGAGGTA TTCGCACTGGATACGACAAAATG-3'; miR-22, forward, 5'-GCAGTTCTTCAGTGGCAAGC-3'; U6, forward, 5'-GCG CGTCGTGAAGCGTTC-3'; universal reverse primer, 5'-GTG CAGGGTCCGAGGT-3'. RT refers to the stem loop primer.

$B$-Raf proto-oncogene serine/threonine kinase $(B R A F)^{V 600 E}$ gene testing. Determination of the BRAF ${ }^{\mathrm{V} 600 \mathrm{E}}$ gene mutation was carried out for all patients with PTC by PCR techniques (20). DNA was isolated from PTC tissues using a DNA Extraction kit (Promega Corporation, Madison, WI, USA), and BRAF gene exon 15 was detected using a BRAF mutant gene detection kit (Amoy Diagnostics Co., LTD, Fujian, China) according to the manufacturer's protocol and the ABI7500 real-time PCR amplifier (Applied Biosystems; Thermo Fisher Inc., Waltham, MA, USA). The primers for amplification of exon 15 of BRAF were designed as follows: Forward, 5'-TCATAATGCTTGCTCTGATAGGA-3' and reverse, 5'-GGCCAAAAATTTAATCAGTGGA-3'). All procedures and analyses were carried out in the biomolecular laboratory of the Hongqi Hospital Affiliated to Mudanjiang Medical University.

Statistical analysis. Data are presented as the means \pm standard deviation (SD). Each experiment was repeated with three times. A two-tailed unpaired Student's t-test was used for comparisons between two groups. One-Way Analysis of Variance (SPSS 13.0; SPSS, Inc., Chicago, IL, USA) followed by a Tukey post hoc test was used to compare more than two groups. Receiver operating characteristic (ROC) curves were used to assess miR-22 as a biomarker, and the area under the curve (AUC) was reported (SPSS version 20.0; IBM Corp., Armonk, NY, USA). Spearman's correlation coefficient was used to determine the correlation between serum miR-22 and tissue miR-22, and serum miR-22 and Tg levels in the tissues of patients with PTC. $\mathrm{P}<0.05$ was considered to indicate a statistically significant difference.

\section{Results}

Serum miR-22 is increased in patients with PTC. RT-qPCR was carried out to detect the levels of miR-22 in the serum of patients with PTC, patients with BTN and healthy controls. Serum miR-22 was slightly increased in patients with BTN $(1.67 \pm 1.18, \mathrm{P}>0.05)$ whereas it was significantly increased in patients with PTC $(24.65 \pm 6.58)$ compared with the healthy controls $(1.00 \pm 0.58)$ (Fig. 1A). In addition, serum miR-22 was significantly increased in patients with PTC and metastasis 
Table I. Clinical features of patients with PTC and healthy controls.

\begin{tabular}{|c|c|c|c|}
\hline Variable & $\begin{array}{c}\text { PTC } \\
\text { patients }\end{array}$ & $\begin{array}{c}\text { BTN } \\
\text { patients }\end{array}$ & $\begin{array}{l}\text { Healthy } \\
\text { controls }\end{array}$ \\
\hline Male/female & $73 / 77$ & $52 / 48$ & $19 / 21$ \\
\hline Age (year) & $55.3 \pm 11.3$ & $49.5 \pm 16.2$ & $53.8 \pm 7.9$ \\
\hline \multicolumn{4}{|c|}{ Tumor size (cm) } \\
\hline$\leq 1$ & 77 & - & - \\
\hline$>1$ & 73 & - & - \\
\hline \multicolumn{4}{|c|}{ Capsular invasion } \\
\hline Yes & 62 & - & - \\
\hline No & 88 & - & - \\
\hline \multicolumn{4}{|c|}{ Lymph node metastasis } \\
\hline Yes & 65 & - & - \\
\hline No & 85 & - & - \\
\hline \multicolumn{4}{|c|}{ No. of cancer foci } \\
\hline Single & 86 & - & - \\
\hline Multiple & 74 & - & - \\
\hline \multicolumn{4}{|c|}{$\mathrm{BRAF}^{\mathrm{V} 600 \mathrm{E}}$ gene } \\
\hline Mutant & 98 & - & - \\
\hline Wild type & 52 & - & - \\
\hline
\end{tabular}

BRAF, B-Raf proto-oncogene serine/threonine kinase; BTN, benign thyroid nodule; PTC, papillary thyroid cancer.

$(9.57 \pm 5.35)$ compared with in patients with PTC who have no metastasis $(1.00 \pm 0.96)(\mathrm{P}<0.01$; Fig. 1B).

Levels of miR-22 in thyroid tissue are increased in patients with PTC. Furthermore, miR-22 expression levels were increased in the thyroid tissue of patients with PTC $(6.01 \pm 1.05)$ compared with in patients with BTN $(1.00 \pm 0.56)$ (Fig. 2A). In addition, miR-22 was increased in patients with PTC and metastasis $(3.86 \pm 0.85)$ compared with in patients

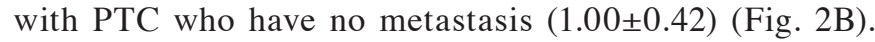
The correlation between serum and thyroid tissue levels of miR-22 was also investigated. Serum miR-22 levels were positively correlated with PTC tissue miR-22 levels $(r=0.592$, $\mathrm{P}<0.001$; Fig. 2C).

Serum miR-22 is enhanced in BRAFV600E mutant patients with PTC. Patients with PTC were further divided according to the presence of a BRAF gene mutation. As shown in Table I, 98 patients were identified as BRAFV600E mutants and 52 patients were identified as wild type BRAF patients. Furthermore, serum miR-22 levels were increased in the BRAFV600E mutant patients with PTC (18.86 +5.12) compared with in the BRAFV600E wild type patients with

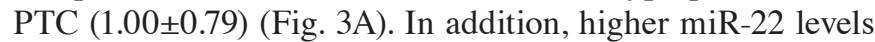
were identified in the thyroid tissues of BRAFV600E mutant patients with PTC $(6.87 \pm 1.35)$ compared with in the $\mathrm{BRAF}^{\mathrm{V} 600 \mathrm{E}}$

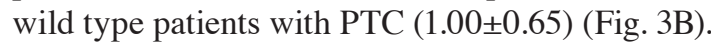

miR-22 is positively correlated with Tg-FNAB levels. Tg determination in the needle washouts (Tg-FNAB) is an
A

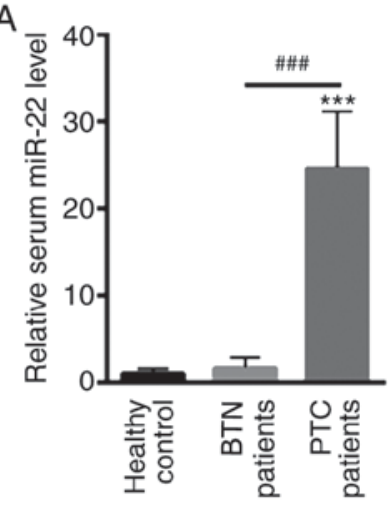

B

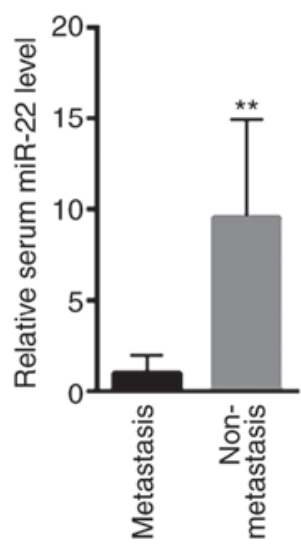

Figure 1. Serum miR-22 is enhanced in patients with PTC. (A) Serum miR-22 was slightly increased in patients with BTN and was significantly increased in patients with PTC compared with the healthy controls. (B) Serum miR-22 was significantly increased in patients with PTC and presenting metastasis compared with in patients with PTC who have no metastasis. ${ }^{* *} \mathrm{P}<0.01$, ${ }^{* * *} \mathrm{P}<0.001$ vs. healthy control; ${ }^{\# \# \#} \mathrm{P}<0.001$ as indicated. BTN, benign thyroid nodule; miR-22, microRNA-22; PTC, papillary thyroid cancer

important method to determine malignancy in the lymph nodes (LNs). The serum expression levels of miR-22 were therefore compared in the different Tg-FNAB groups. Briefly, 30 patients were included in the $\leq 1 \mathrm{ng} / \mathrm{ml} \mathrm{Tg-FNAB}$ group and 62 patients were included in the $1-10 \mathrm{ng} / \mathrm{ml} \mathrm{Tg}-\mathrm{FNAB}$ group, whereas 58 patients were included in $>10 \mathrm{ng} / \mathrm{ml} \mathrm{Tg}-\mathrm{FNAB}$ group. As shown in Fig. 4A, serum miR-22 was much lower in patients with PTC with $\leq 1 \mathrm{ng} / \mathrm{ml} \mathrm{Tg}-\mathrm{FNAB}(1.00 \pm 0.64)$. Conversely, serum miR-22 was much higher in patients with PTC with 1-10 ng/ml Tg-FNAB $(5.23 \pm 1.03)$ and was highest in patients with PTC with $>10 \mathrm{ng} / \mathrm{ml}$ Tg-FNAB $(16.24 \pm 4.36)$ (Fig. 4A). Furthermore, serum miR-22 was demonstrated to be positively correlated with Tg levels in patients with PTC $(r=0.423, P<0.001$; Fig. 4B).

miR-22 differentiates patients with PTC from healthy controls. Finally, a ROC analysis was carried out to evaluate whether serum miR-22 expression could be used as a potential biomarker to discern patients with PTC from healthy controls. Data revealed that serum miR-22 could differentiate patients with PTC from healthy controls, with an AUC of 0.942 (95\% confidence interval: 0.858-1.000; P<0.001; Fig. 5).

\section{Discussion}

The identification of novel biomarkers for patients with PTC is crucial $(21,22)$. It has been reported that a BRAF mutation, assessed after FNA, is an important biomarker for aggressive PTC (23). Furthermore, p27, p21, cyclin D1, osteopontin and E-cadherin have also been suggested as potential biomarkers for the diagnosis of PTC $(24,25)$. However, these biomarkers are limited due to their poor clinical applications.

Due to their stability and abundance in the circulatory system, circulating miRNAs have been revealed as important biomarkers for various types of cancer $(11,12)$. To the best of our knowledge, the present study is the first to demonstrate increased miR-22 levels in the serum of patients with PTC compared with in patients with BTN and healthy controls. 

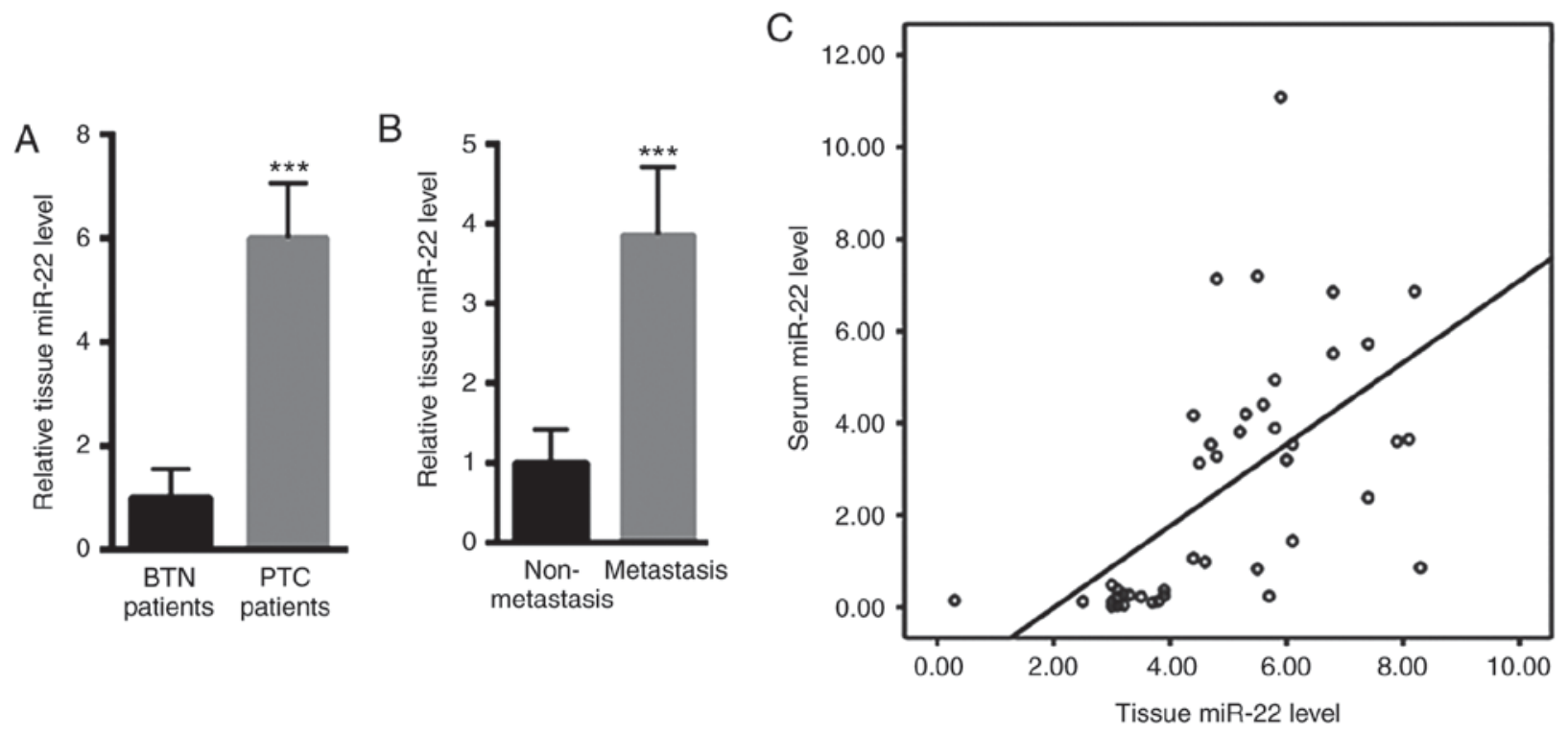

Figure 2. Levels of miR-22 in thyroid tissue are increased in patients with PTC. (A) Expression levels of miR-22 were increased in the thyroid tissue from patients with PTC compared with in patients with BTN. (B) miR-22 was increased in the thyroid tissue from patients with PTC and metastasis compared with in patients with PTC who have no metastasis. (C) Spearman's correlation coefficient assay demonstrated that serum miR-22 levels were positively correlated with tissue miR-22 levels in patients with PTC. ${ }^{* * * *} \mathrm{P}<0.001 \mathrm{vs.} \mathrm{BTN}$ patients or non-metastatic patients. BTN, benign thyroid nodule; miR-22, microRNA-22; PTC, papillary thyroid cancer.
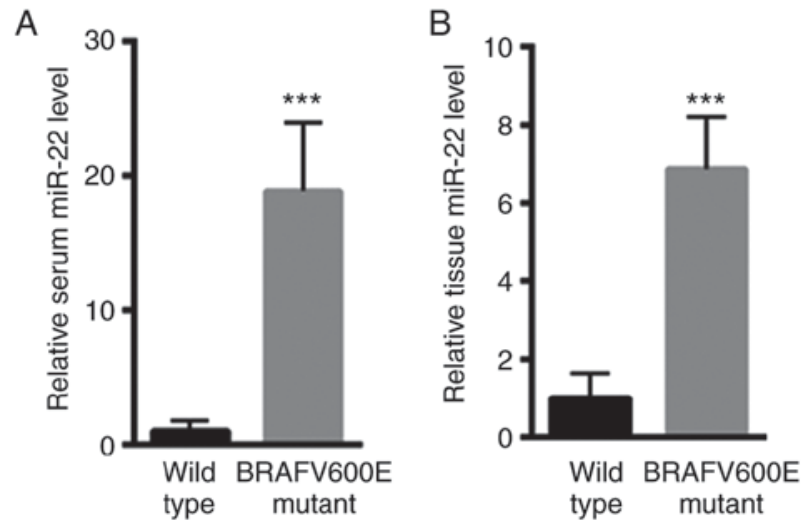

Figure 3. Serum miR-22 is enhanced in BRAFV600E mutant patients with PTC. (A) Serum miR-22 levels were increased in the BRAFV600E mutant patients with PTC compared with in the BRAFV600E wild type patients with PTC. (B) Higher miR-22 levels were identified in the thyroid tissues from the BRAFV600E mutant patients with PTC compared with in the BRAFV600E wild type patients with PTC. ${ }^{* * *} \mathrm{P}<0.001$ vs. wild type patients. BRAF, B-Raf proto-oncogene serine/threonine kinase; miR-22, microRNA-22; PTC, papillary thyroid cancer.

Similarly, the levels of miR-22 were increased in thyroid tissues of patients with PTC compared with in patients with BTN. These observations indicated that miR-22 may have an oncogenic role in the development of PTC. In addition, cancer metastasis is still a major cause of mortality for patients (26). Identifying a novel diagnostic tool or therapeutic intervention that would serve a key role in the prevention of PTC is therefore crucial (27). In the present study, serum and tissue miR-22 levels were significantly increased in patients with PTC and metastasis compared with in patients with PTC who had no metastasis.

The T1799A nucleotide mutation in the BRAF gene is a key oncogenic mutation in patients with PTC $(28,29)$. It has been estimated that $45 \%$ of patients with PTC have this mutation, which corresponds to a valine-to-glutamic acid exchange in codon 600 of the BRAF protein (BRAFV600E). This mutation increases serine/threonine protein kinase activities and constitutively activates the mitogen-activated protein kinase signaling pathway $(30,31)$. Therefore, BRAFV600E represents an important prognostic marker for patients with PTC $(30,31)$. The expression levels of miR-22 in serum and tissue samples from patients with PTC and the BRAFV600E mutation were also analyzed and compared with the wild type patients. Results demonstrated that serum and tissue miR-22 levels were increased in patients with PTC with the BRAFV600E mutation, thus indicating that the upregulation of miR-22 may be positively associated with the risk of PTC.

Furthermore, Tg-FNAB is another important method for determining LN metastases $(32,33)$. However, $5-10 \%$ of FNABs have been demonstrated to have non-diagnostic value and $6-8 \%$ to be false negatives (34). The present study revealed that serum miR-22 expression was significantly augmented in patients with PTC with 1-10 ng/ml Tg-FNAB and $>10 \mathrm{ng} / \mathrm{ml}$ Tg-FNAB, thus suggesting that serum miR-22 may be used as an auxiliary non-invasive diagnostic method in line with Tg-FNAB levels. The ROC analysis also demonstrated that serum miR-22 expression was able to directly differentiate patients with PTC from healthy controls.

A previous study proposed that circulating miR-22 is associated with the etiology of liver injury in patients with human immunodeficiency virus (HIV), which suggests that miR-22 circulating levels may be an independent predictor of liver injury in patients with HIV (35). Furthermore, serum miR-22-5p is correlated with acute myocardial infarction (AMI), which suggests that miR-22 could also be a promising biomarker for the diagnosis of AMI (36). In comparison with these studies, the present study attempted 

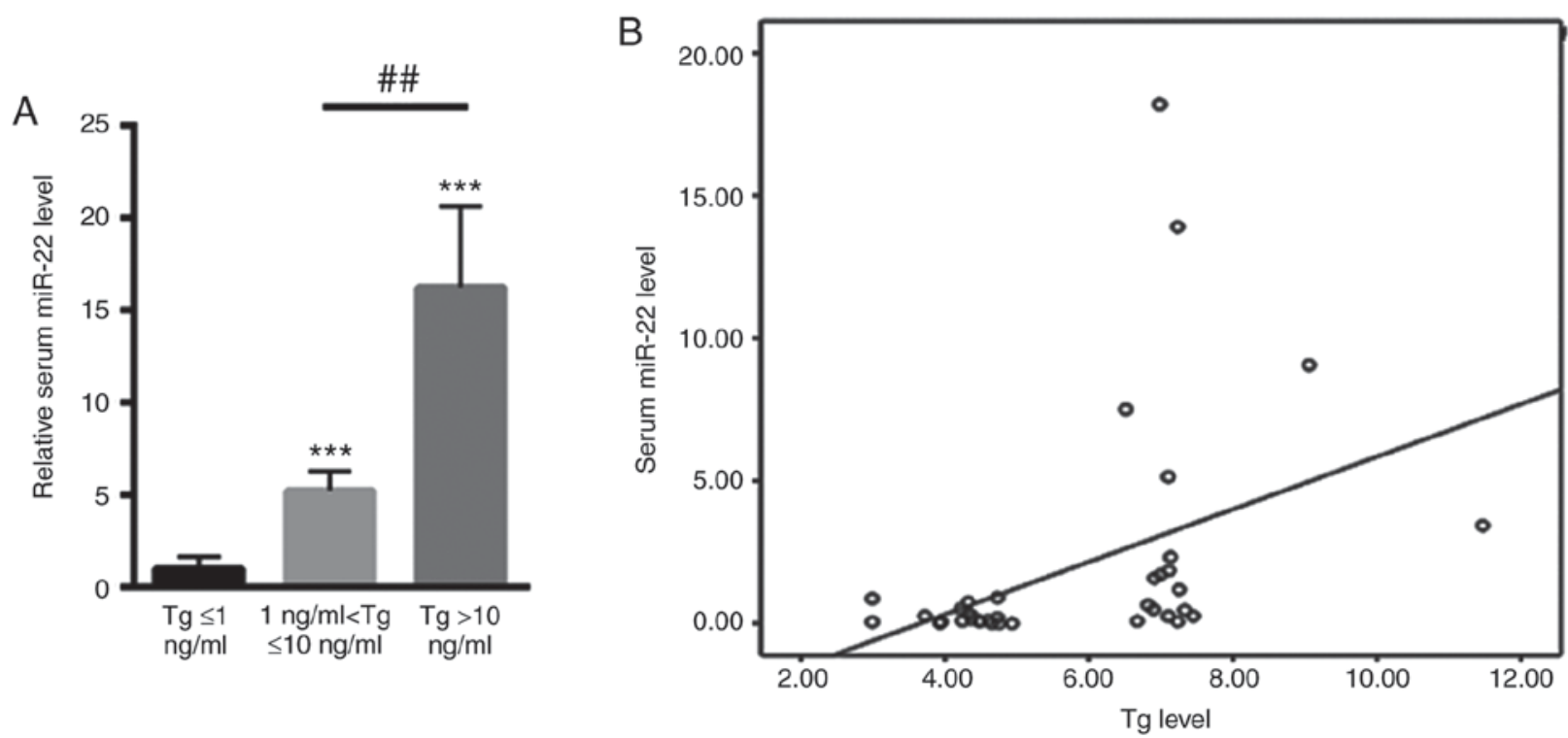

Figure 4. miR-22 is positively correlated with Tg-FNAB levels. (A) Reverse transcription-quantitative polymerase chain reaction (RT-qPCR) analysis was carried out to determine the serum expression levels of miR-22 in PTC patients with $\leq 1 \mathrm{ng} / \mathrm{ml} \mathrm{Tg-FNAB,} 1-10 \mathrm{ng} / \mathrm{ml} \mathrm{Tg}-\mathrm{FNAB}$ and $>10 \mathrm{ng} / \mathrm{ml} \mathrm{Tg}-\mathrm{FNAB}$. (B) Spearman's correlation coefficient assay demonstrated that serum miR-22 was positively correlated with $\mathrm{Tg}$ levels in patients with PTC. ${ }^{* * * *} \mathrm{P}<0.001 \mathrm{vs} . \leq 1$ $\mathrm{ng} / \mathrm{ml} \mathrm{Tg} ;{ }^{\# \#} \mathrm{P}<0.01$ as indicated. miR-22, microRNA-22, PTC, papillary thyroid cancer; Tg-FNAB, thyroglobulin-fine needle aspiration biopsy.

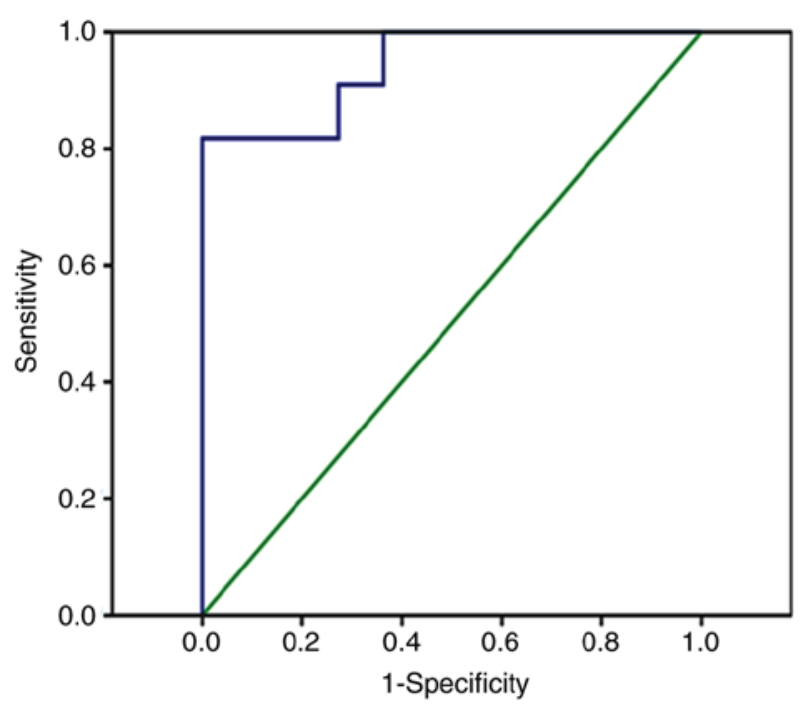

Figure 5. Receiver operating characteristic analysis reveals that microRNA-22 differentiates patients with papillary thyroid cancer from healthy controls.

to determine whether serum miR-22 expression could be a potential biomarker for patients with PTC. Other conditions may also cause an increase in serum miR-22 $(1,2)$. The present study mainly focused on miR-22 expression in patients with PTC; a detailed analysis of miR-22 expression in serum and tissues was conducted from patients previously categorized into different groups. miR-22 levels were assessed in 150 patients with PTC, 100 patients with BTN and 40 normal subjects. The results revealed a significant increase in miR-22 expression in the serum and thyroid tissues of patients with PTC, which was associated with the presence of metastasis and the BRAFV600E mutation. ROC analysis also demonstrated that serum miR-22 may be used as a biomarker for screening patients with PTC. These novel findings are interesting and may be of significant clinical importance.

In conclusion, to the best of our knowledge, the present study was the first to reveal that miR-22 serum levels may represent a novel biomarker for patients with PTC that does not involve any invasive procedure. However, a larger number of samples should be included in a future study. In addition, detailed analysis of the potential relationship between serum levels of miR-22 and the clinicopathological features of patients should be considered.

\section{Acknowledgements}

Not applicable.

\section{Funding}

The present study was supported by a grant from the $\mathrm{PhD}$ startup fund of Mudanjiang Medical University (grant no. MMU-20170615).

\section{Availability of data and materials}

The datasets used and/or analyzed during the present study are available from the corresponding author upon reasonable request.

\section{Authors' contributions}

DW performed the experiments and analyzed the data. CG, TK, GM, and JL performed the RT-qPCR experiments. YS designed the experiments, analyzed the data and gave final approval of the published version. All authors read and approved the final manuscript. 


\section{Ethics approval and consent to participate}

The present study was approved by the Research Ethics Committee of Hongqi Hospital Affiliated to Mudanjiang Medical University, Mudanjiang City (HQH-2016014, Mudanjiang City, China), and all the patients have provided written informed consent for this study.

\section{Patient consent for publication}

All patients provided consent for publication of their data.

\section{Competing interests}

The authors declare that they have no competing interests.

\section{References}

1. Haugen BR, Sawka AM, Alexander EK, Bible KC, Caturegli P, Doherty GM, Mandel SJ, Morris JC, Nassar A, Pacini F, et al: American thyroid association guidelines on the management of thyroid nodules and differentiated thyroid cancer task force review and recommendation on the proposed renaming of encapsulated follicular variant papillary thyroid carcinoma without invasion to noninvasive follicular thyroid neoplasm with papillary-like nuclear features. Thyroid 27: 481-483, 2017.

2. Hao Y, Pan C, Chen W, Zhu WZ and Qi JP: Differentiation between malignant and benign thyroid nodules and stratification of papillary thyroid cancer with aggressive histological features: Whole-lesion diffusion-weighted imaging histogram analysis. J Magn Reson Imaging 44: 1546-1555, 2016.

3. Fusco A, Chiappetta G, Hui P, Rostan GG, Golden L, Kinder BK, Dillon DA, Giuliano A, Cirafici AM, Santoro M, Rosai J, et al: Assessment of RET/PTC oncogene activation and clonality in thyroid nodules with incomplete morphological evidence of papillary carcinoma: A search for the early precursors of papillary cancer. Am J Pathol 160: 2157-2167, 2002

4. Jolly LA, Novitskiy S, Owens P, Massoll N, Cheng N, Fang W, Moses HL and Franco AT: Fibroblast-mediated collagen remodeling within the tumor microenvironment facilitates progression of thyroid cancers driven by BrafV600E and Pten loss. Cancer Res 76: 1804-1813, 2016.

5. Brace MD, Wang J, Petten M, Bullock MJ, Makki F, Trites J, Taylor SM and Hart RD: Differential expression of transforming growth factor-beta in benign vs. papillary thyroid cancer nodules a potential diagnostic tool? J Otolaryngol Head Neck Surg 43: 22, 2014.

6. Hwang S, Shin DY, Kim EK, Yang WI, Byun JW, Lee SJ, Kim G, Im SJ and Lee EJ: Focal lymphocytic thyroiditis nodules share the features of papillary thyroid cancer on ultrasound. Yonsei Med J 56: 1338-1344, 2015

7. Baldini E, Tuccilli C, Prinzi N, Sorrenti S, Falvo L, Vito CD, Catania A, Tartaglia F, Mocini R, Coccaro C, et al: Deregulated expression of Aurora kinases is not a prognostic biomarker in papillary thyroid cancer patients. PLoS One 10: e0121514, 2015.

8. Komatsu S, Ichikawa D, Takeshita H, Morimura R, Hirajima S, Tsujiura M, Kawaguchi T, Miyamae M, Nagata H, Hirotaka K, et al: Circulating miR-18a: A sensitive cancer screening biomarker in human cancer. In Vivo 28: 293-297, 2014.

9. Kurashige J, Mima K, Sawada G, Takahashi Y, Eguchi H, Sugimachi K, Mori M, Yanagihara K, Yashiro $M$, Hirakawa $\mathrm{K}$, et al: Epigenetic modulation and repression of miR-200b by cancer-associated fibroblasts contribute to cancer invasion and peritoneal dissemination in gastric cancer. Carcinogenesis 36: 133-141, 2015.

10. Wang XZ, Hang YK, Liu JB, Hou YQ, Wang N, Wang MJ: Over-expression of microRNA-375 inhibits papillary thyroid carcinoma cell proliferation and induces cell apoptosis by targeting ERBB2. J Pharmacol Sci 130: 78-84, 2016.

11. Chou CK, Liu RT and Kang HY: MicroRNA-146b: A novel biomarker and therapeutic target for human papillary thyroid cancer. Int J Mol Sci 18, 2017.
12. Dai L, Wang Y, Chen L, Zheng J, Li J and Wu X: MiR-221, a potential prognostic biomarker for recurrence in papillary thyroid cancer. World J Surg Oncol 15: 11, 2017.

13. Xiong Y, Kotian S, Zeiger MA, Zhang L and Kebebew E: miR-126-3p inhibits thyroid cancer cell growth and metastasis, and is associated with aggressive thyroid cancer. PLoS One 10: $\mathrm{e} 0130496,2015$.

14. Lee JC, Zhao JT, Clifton-Bligh RJ, Gill A, Gundara JS, Ip JC, Glover A, Sywak MS, Delbridge LW, Robinson BG and Sidhu SB MicroRNA-222 and microRNA-146b are tissue and circulating biomarkers of recurrent papillary thyroid cancer. Cancer 119: 4358-4365, 2013.

15. Liu H, Huang $X$ and Ye T: MiR-22 down-regulates the proto-oncogene ATP citrate lyase to inhibit the growth and metastasis of breast cancer. Am J Transl Res 10: 659-669, 2018.

16. Chen Z, Shen A, Liu L, Chen Y, Chu J, Cai Q, Qi F, Sferra TJ and Peng J: Pien Tze Huang induces apoptosis and inhibits proliferation of 5-fluorouracil-resistant colorectal carcinoma cells via increasing miR-22 expression. Exp Ther Med 14: 3533-3540, 2017.

17. Domper Arnal MJ, Ferrandez Arenas Á and Lanas Arbeloa Á: Esophageal cancer: Risk factors, screening and endoscopic treatment in Western and Eastern countries. World J Gastroenterol 21: 7933-7943, 2015.

18. Benjamin H, Schnitzer-Perlman T, Shtabsky A, VandenBussche CJ, Ali SZ, Kolar Z, Pagni F; Rosetta Genomics Group, Bar D and Meiri E: Analytical validity of a microRNA-based assay for diagnosing indeterminate thyroid FNA smears from routinely prepared cytology slides. Cancer Cytopathol 124: 711-721, 2016.

19. Livak KJ and Schmittgen TD: Analysis of relative gene expression data using real-time quantitative PCR and the 2(-Delta Delta C(T)) method. Methods 25: 402-408, 2001.

20. Qu K, Pan Q, Zhang X, Rodriguez L, Zhang K, Li H, Ho A Sanders H, Sferruzza A, Cheng SM, et al: Detection of BRAF V600 mutations in metastatic melanoma: Comparison of the Cobas 4800 and Sanger sequencing assays. J Mol Diagn 15: 790-795, 2013.

21. Yoon JH, Lee HS, Kim EK, Moon HJ and Kwak JY: Thyroid nodules: Nondiagnostic cytologic results according to thyroid imaging reporting and data system before and after application of the bethesda system. Radiology 276: 579-587, 2015.

22. Moon HJ, Kim EK, Yoon JH and Kwak JY: Malignancy risk stratification in thyroid nodules with nondiagnostic results at cytologic examination: Combination of thyroid imaging reporting and data system and the Bethesda System. Radiology 274: 287-295, 2015.

23. Zhang J, Liu BJ, Xu HX, Xu JM, Zhang YF, Liu C, Wu J, Sun LP, Guo LH, Liu LN, et al: Prospective validation of an ultrasound-based thyroid imaging reporting and data system (TI-RADS) on 3980 thyroid nodules. Int J Clin Exp Med 8: 5911-5917, 2015

24. Rodolico V, Cabibi D, Pizzolanti G, Richiusa P, Gebbia N, Martorana A, Russo A, Amato MC, Galluzzo A and Giordano C: BRAF V600E mutation and p27 kip1 expression in papillary carcinomas of the thyroid $<$ or $=1 \mathrm{~cm}$ and their paired lymph node metastases. Cancer 110: 1218-1226, 2007.

25. Pesutic-Pisac V, Punda A, Gluncic I, Bedeković V, Kragić AP and Kunac N: Cyclin D1 and p27 expression as prognostic factor in papillary carcinoma of thyroid: Association with clinicopathological parameters. Croat Med J 49: 643-649, 2008.

26. Nguyen QT, Lee EJ, Huang MG, Park YI, Khullar A and Plodkowski RA: Diagnosis and treatment of patients with thyroid cancer. Am Health Drug Benefits 8: 30-40, 2015.

27. Baldini E, Sorrenti S, Tuccilli C, Prinzi N, Coccaro C, Catania A, Filippini A, Bononi M, Antoni ED, D'Armiento M and Ulisse S: Emerging molecular markers for the prognosis of differentiated thyroid cancer patients. Int J Surg 12 (Suppl): S52-S56, 2014.

28. Cohen Y, Xing M, Mambo E, Guo Z, Wu G, Trink B, Beller U, Westra WH, Ladenson PW and Sidransky D: BRAF mutation in papillary thyroid carcinoma. J Natl Cancer Inst 95: 625-627, 2003.

29. Kimura ET, Nikiforova MN, Zhu Z, Knauf JA, Nikiforov YE and Fagin JA: High prevalence of BRAF mutations in thyroid cancer: Genetic evidence for constitutive activation of the RET/PTC-RAS-BRAF signaling pathway in papillary thyroid carcinoma. Cancer Res 63: 1454-1457, 2003.

30. Davies H, Bignell GR, Cox C, Stephens P, Edkins S, Clegg S, Teague J, Woffendin H, Garnett MJ, Bottomley W, et al: Mutations of the BRAF gene in human cancer. Nature 417: 949-954, 2002

31. Millington GWM: Mutations of the BRAF gene in human cancer, by Davies et al. (Nature 2002; 417: 949-54). Clin Exp Dermatol 38: 222-223, 2013. 
32. Li QK, Nugent SL, Straseski J, Cooper D, Riedel S, Askin FB and Sokoll LJ: Thyroglobulin measurements in fine-needle aspiration cytology of lymph nodes for the detection of metastatic papillary thyroid carcinoma. Cancer Cytopathol 121: 440-448, 2013.

33. Hanna AN, Michael CW and Jing X: Mixed medullary-follicular carcinoma of the thyroid: Diagnostic dilemmas in fine-needle aspiration cytology. Diagn Cytopathol 39: 862-865, 2011.

34. Frasoldati A and Valcavi R: Challenges in neck ultrasonography: Lymphadenopathy and parathyroid glands. Endocr Pract 10: 261-268, 2004

35. Anadol E, Schierwagen R, Elfimova N, Tack K Schwarze-Zander C, Eischeid H, Noetel A, Boesecke C, Jansen C, Dold L, et al: Circulating microRNAs as a marker for liver injury in human immunodeficiency virus patients. Hepatology 61: 46-55, 2015.
36. Maciejak A, Kiliszek M, Opolski G, Segiet A, Matlak K, Dobrzycki S, Tulacz D, Sygitowicz G, Burzynska B, Gora M: miR-22-5p revealed as a potential biomarker involved in the acute phase of myocardial infarction via profiling of circulating microRNAs. Mol Med Rep 14: 2867-2875, 2016.

cc) (i) $९$ This work is licensed under a Creative Commons Attribution-NonCommercial-NoDerivatives 4.0 International (CC BY-NC-ND 4.0) License. 